\title{
Simultaneous bilateral primary diffuse malignant uveal melanoma: case report with pathological examination
}

\author{
SHIGEO TSUKAHARA, ' KAICHI WAKUI, ${ }^{2}$ AND SHINOBU OHZEKI \\ From the 'Department of Ophthalmology, Yamanashi Medical College, Tamaho, Yamanashi, 409-38 Japan; \\ ${ }^{2}$ the Eye Department, Tokyo Senin Hoken Hospital, Tokyo, 108 Japan; $^{3}$ and the Ey'e Clinic, Nagaoka, \\ Niigata, 940 Japan
}

SUMmARY A 50-year-old Japanese housewife became blind owing to bilateral diffuse malignant melanoma of the choroid, ciliary body, and iris. These were histologically proved when enucleation was required because of blind painful eyes with raised intraocular pressures. She presented with reduced visual acuity and night blindness. Small scattered atrophic areas were observed between disc and macula on both sides, which fluorescein angiography showed were due to patchy atrophy of the retinal pigment epithelium. There was reduced amplitude in the electroretinogram. Inferior retinal detachments soon appeared and spread to become total. Pathological examination showed diffusely thickened choroid on both sides, due to infiltration by epithelioid and spindle-shaped malignant melanoma cells, which also affected the thickened ciliary body and iris diffusely. A carcinoma of the uterus successfully treated three years previously and the probably multicentric origin of the malignancy in each eye, and its bilateral occurrence, suggest a tumour-producing tendency in this patient, an interpretation which also applies to one of the other eight reported cases.

This case of simultaneous, bilateral, histologically proved diffuse malignant choroidal melanoma in a 50-year-old Japanese housewife is being described because of the rarity of melanomata in the Japanese compared with Europeans and North Americans, the extreme rarity world wide of bilateral cases, and also because of the very unusual clinical presentation. Because she had a carcinoma of uterus three years previously a general predisposition to tumour formation is suggested in our patient (and others in the literature). ${ }^{1-3}$

It has been estimated that 0.02 to $0.06 \%$ of all patients with eye disease have choroidal melanoma. ${ }^{4}$ The frequency of occurrence of ocular malignant melanoma in the general population of the USA is around 5 per million, ${ }^{5}$ while in Japan the only relevant report can be interpreted as suggesting an incidence of 0.5 per million, or $1 / 10$ th the USA incidence. Consistent with these figures are those of

Correspondence to Professor Shigeo Tsukahara, Department of Ophthalmology, Yamanashi Medical College, Tamaho, Yamanasi, 409-38 Japan.
Hogan and Zimmerman ${ }^{6}$ giving a Caucasian: nonCaucasian ratio of 250:1 in cases of melanoma in the Washington Registry of Ophthalmic Pathology, and a ratio of 165:1 for Caucasians: Negroes. ${ }^{\circ}$

Bilateral cases of primary malignant melanoma are very unusual. Until 1949 Cordes and Cook's detailed review revealed only six reports, of which two may have been of tuberculous lesions rather than malignant melanomas. ${ }^{7}$ In three others the diagnosis was presumed on clinical evidence only, but in the sixth case $^{8}$ there was histological proof. They added a case of simultaneous melanoma in the right iris and left choroid, both confirmed histologically. Reese ${ }^{9}$ mentions a bilateral case. Of particular interest to us is the patient with bilateral proved choroidal melanoma described by Wiesinger $e t$ al. ' because of the coexistence of meningioma and leukaemia. Three further cases of bilateral choroidal malignant melanomas, verified histologically, have been reported more recently. ${ }^{10-12}$ Shammas and Watzke ${ }^{2}$ estimated an incidence of bilateral cases of one per 50 million lifetimes, implying an occurrence once in 18 years in the whole USA. 
Fig. 1 Fluorescein angiography: late phase (18 seconds). Multiple patchy windows show in pigment epithelium, with increased leakiness of choroidal (tumour) vasculature.

Fig. 2 Left eye. Cyst arising in posterior layers of iris protruding at pupil margin at $10 o^{\prime}$ clock. $(\times 7)$.
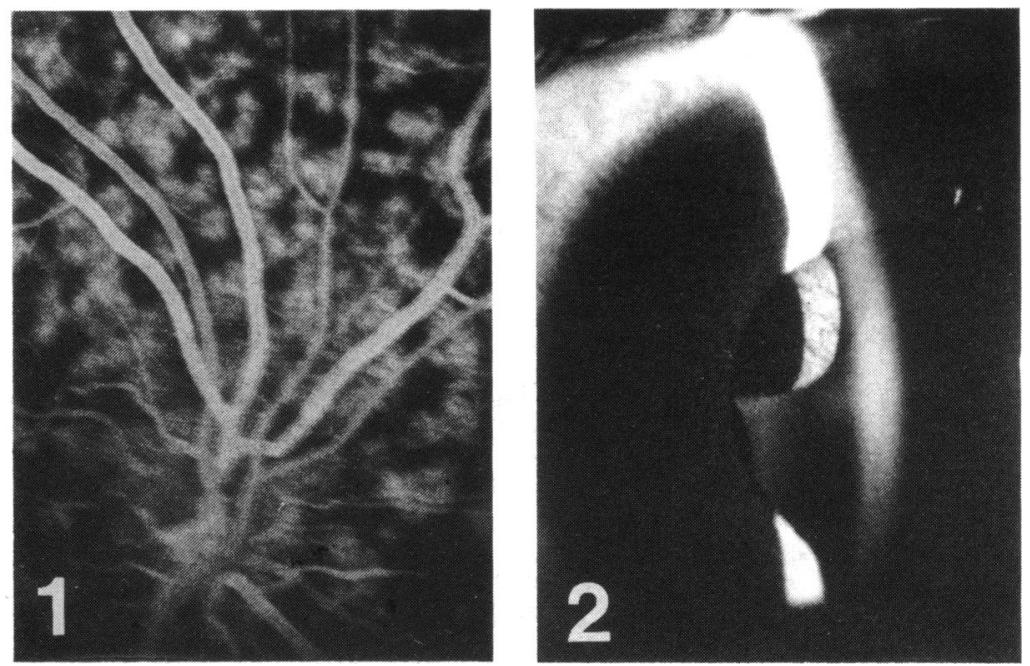

\section{Case report}

A 50-year-old Japanese housewife presented to the Branch Hospital of Tokyo University with blurred vision and difficulty in coping with light-dark transition for one month. She had no previous eye disease, and the only important abnormality in her general health was an hysterectomy three years previously for uterine carcinoma, followed by 40 days' treatment with intravenus Endoxan or Cytoxan (cyclophosphamide) $400 \mathrm{mg}$ daily. The family history was negative and her parents were not consanguineous.

Positive ophthalmic findings were as follows. Corrected visual acuities were 0.4 in the right eye and 0.5 in the left. Multiple, atrophic patches of various sizes were scattered between disc and macula on both sides (recognised in retrospect as being unusual clinical features of diffuse malignant melanoma). On the right side drusen-like but white patches were also present in the macular area. Fluorescein angiography showed patchy atrophy of the retinal pigment epithelium (Fig. 1).

Dark adaptation curves had a reduced scotopic component, and the electroretinogram (ERG) showed reduced amplitude to stimuli of all intensities.

Negative findings at presentation were normal fields, pupil reactions, and ocular movements, and normal ocular tensions: Schiøtz right eye $6.5 / 5.5 \mathrm{~g}$, left eye $6 \cdot 0 / 5 \cdot 5 \mathrm{~g}$.

At that time the differential diagnosis included tapetoretinal dystrophy, metastatic carcinoma, and cyclophosphamide toxicity.

During the next two months, although the visual acuity (VA) improved to 0.7 in each eye, large 


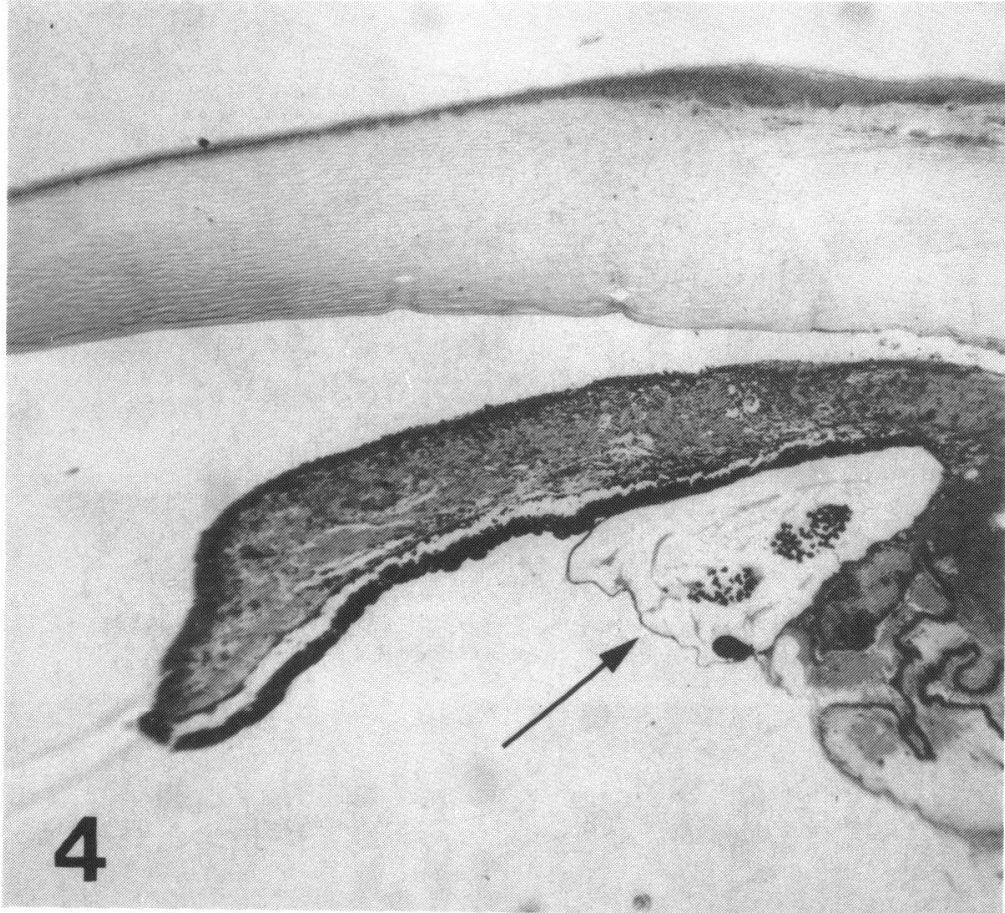

Fig. 4 Cross-section of the anterior part in right eye. Arrow indicates the formation of iris cyst including pigment-granulecontaining cells. (Haematoxylin and eosin, $\times 30$ ).

bilateral inferior retinal detachments without holes appeared, with constricted fields, a more diminished ERG, and corresponding with the patient's increasing difficulty in seeing in dull illumination, a remarkably decreased dark-adaptation curve. A month later the VAs had diminished to hand movements RE and
0.01 LE because of an increase upwards in the extent of the retinal detachments, which probably also accounted for indistinctness ophthalmoscopically of the scattered white atrophic patches at the posterior pole, and reduced intraocular pressure (Schiøtz: RE $12 \cdot 0 / 5 \cdot 5 \mathrm{~g}$, LE $10 \cdot 0 / 5 \cdot 5 \mathrm{~g}$ ).

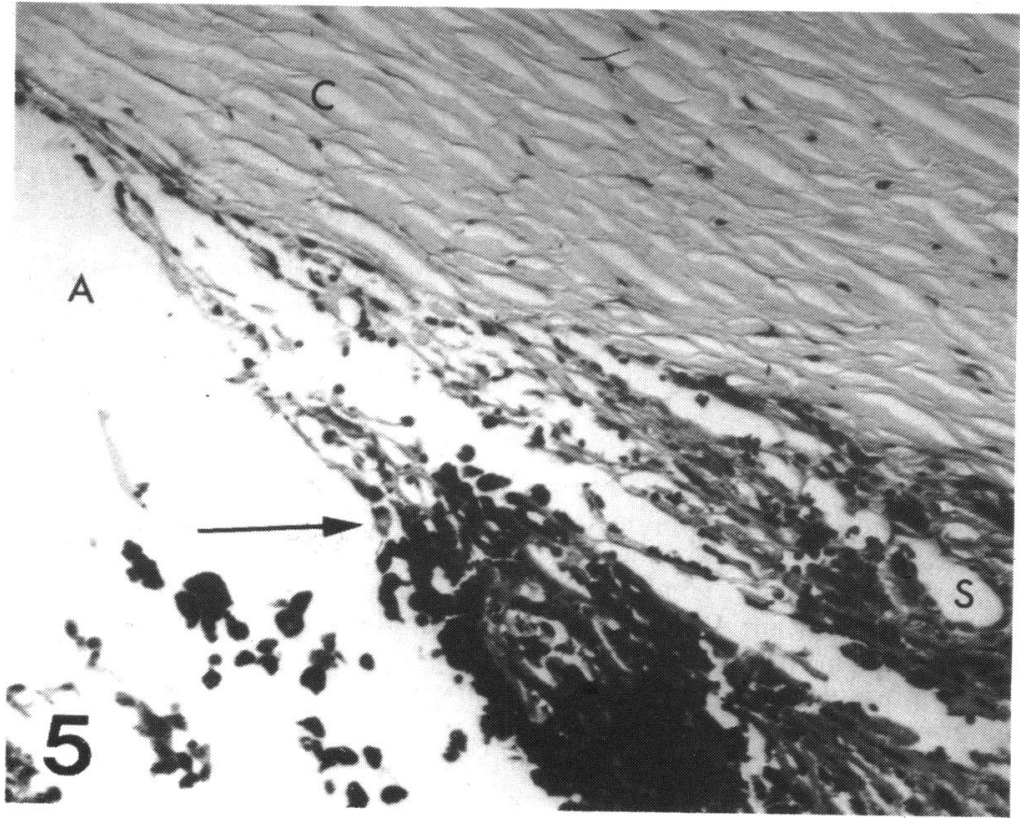

Fig. 5 Cross-section of the chamber angle in left eye. Arrow indicates melanoma cells infiltrating the trabecular meshwork.

$\mathrm{A}=$ anterior chamber. $\mathrm{C}=$ cornea . $\mathrm{S}=$ Schlemm's canal.

(Haematoxylin and eosin, $\times 187$ ). 
Fig. 6 Cross-section of the choroid in right eye. a. Abundant pigment containing cells form nodule. $\mathrm{Sc}=$ Sclera. $\mathrm{b}$. High magnification of tumour cells. c. The same. (Haematoxylin and eosin, $\times 700)$.
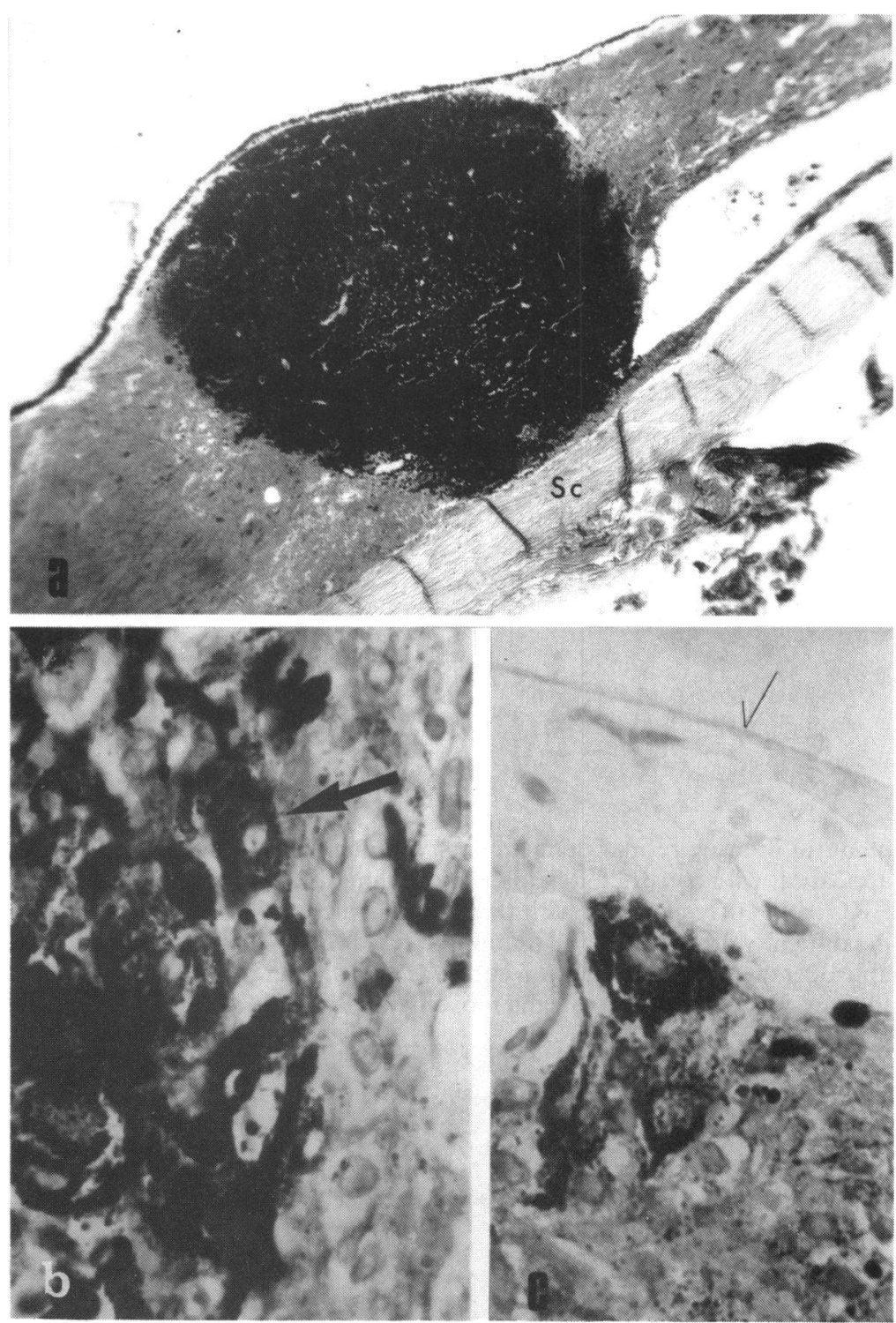

48 hours after ${ }^{40} \mathrm{Ga}$ by intravenous injection, showed an abnormal count in the region of both eyes.

About 11 months after her first attendance the left eye had to be enucleated because pain was added to blindness, with ocular tensions of Schiøtz 4.0/10 g due to shallow anterior chambers and widespread goniosynechiae. Enucleation of the right eye had to be undertaken two months later for the same reason.

PATHOLOGICAL FINDINGS

Gross examination

The positive findings were total retinal detachments in both eyes, with diffusely thickened choroid and 
ciliary body (Fig. 3a, b). In the right eye a pigmented nodule $3.4-4.0 \mathrm{~mm}$ in diameter and $1.7-2.0 \mathrm{~mm}$ in thickness was found three disc diameters temporal to the disc; another, with similar dimensions, was present on the nasal side adjacent to the ciliary body (Fig. 3a).

\section{Microscopic examination}

The positive findings were as follows:

(i) Iris. Epithelial malignant melanoma cells with abundant dark brown pigment granules had diffusely thickened the iris (Fig. 3). There was a cyst in the right eye at the root of the iris and its wall was partly adherent to the ciliary body. Its contents were an amorphous mass with small numbers of pigmentcontaining cells. In the left eye a membranous structure protruded towards the posterior chamber, presumptively part of an iris cyst (Fig. 4).

(ii) Angle of anterior chamber. Polygonal pigmentcontaining cells had infiltrated the trabecular meshwork and the area between it and the base of iris (Fig. 5).

(iii) Ciliary body and choroid were both thickened greatly by an infiltration of spindle and epitheloid cells, occasionally in mitosis, containing pigment granules which may have obscured nucleoli. Pigment granules measuring $0.5-0.7 \mu \mathrm{m}$, were of varying density and gave a negative Prussian blue reaction. The increased choroidal thickness was more marked in the left eye $(0.7 \mathrm{~mm}$ when dehydrated) compared with the right $(0.4 \mathrm{~mm})$. The normal thickness is $0.1 \mathrm{~mm}$. The nodules visible macroscopically in the right eye (Fig. 3) were confirmed to be of malignant melanoma tissue (Fig. 6a, b, c).

(iv) Retinae were totally detached and degenerate.
Acellular, serous, subretinal exudate was present. The pigment epithelium was partially preserved.

(v) Sclera and optic nerve. Spindle cells with elongated nuclei had infiltrated the region of the perforating scleral vessels, including the short ciliary arteries near the optic nerve head, which however was itself uninvolved in tumour spread (Fig. 7). No local spread of tumour beyond the sclera could be detected microscopically or macroscopically.

The cellular morphology corresponded with the 'mixed-cell type' of Callender's classification. ${ }^{13}$

\section{Discussion}

The clinical diagnosis was very difficult indeed because the melanomas were diffuse, causing very unusual symptoms and signs, and were bilateral, the latter condition being extremely rare. However, tumour was suspected. The previously treated carcinoma of uterus could well have recurred and caused bilateral metastatic deposits in the choroid, albeit with very unusual manifestations. Similarly, a toxic effect on the retina of the anticancer drug cyclophosphamide was considered as a possible cause. However, we suspect a tumour-producing tendency exists in this patient, first because both eyes are affected, secondly because within each eye we think a multiplicity of neoplastic centres arose, and thirdly the patient had a carcinoma of the uterus three years previously. Accordingly we suggest that it is no coincidence that another well-documented case of bilateral ocular malignant melanoma had a meningioma at the base of skull and a stem-cell leukaemia, which caused her death. ${ }^{\prime}$ Recently a case of bilateral uveal melanoma in a 60 -year-old woman

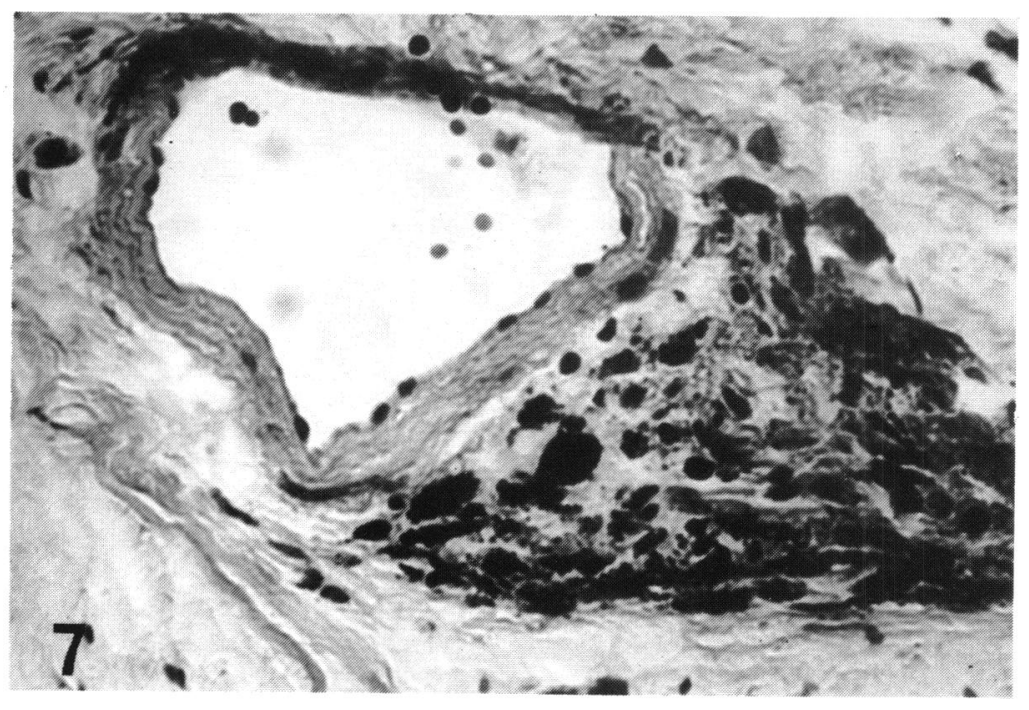

Fig. 7 Cross-section of short posterior ciliary artery, indicating the infiltration of tumour cells in the surrounding tissue. (Haematoxylin and eosin, $\times 700)$. 
in association with primary bilateral ovarian carcinoma was described. ${ }^{3}$ These cases seem to suggest the general predisposition to tumour formation. Analogously, the association between the retinoblastoma gene and subsequent development of tumours elsewhere, even in non-irradiated tissues, would support this suggestion. ${ }^{14}$

\section{References}

1 Wiesinger H, Phipps GW, Du Pont Geurry III. Bilateral melanoma of the choroid associated with leukaemia and meningioma. Arch Ophthalmol 1959; 62: 889-93.

2 Shammas HF, Watzke RC. Bilateral choroidal melanomas. Arch Ophthalmol 1977; 95: 617-23.

3 Mullaney J, Mooney D, O'Connor M, McDonald GSA. Bilateral ovarian carcinoma with bilateral uveal melanoma. $B r J$ Ophthalmol 1984; 68: 261-7.

4 Duke-Elder WS. Textbook of ophthalmology. St Louis: Mosby, 1971: 3: 2479.
5 Cutler SJ, Young JL. Third national cancer survey: incidence data. National Cancer Institute Monograph No. 41. Washington: United States Government Printing Office, 1975: 1-454.

6 Hogan MJ, Zimmerman LE. Ophthalmic pathology 2nd ed. Philadelphia: Saunders, 1962: 413.

7 Cordes FC, Cook RD. Simultaneous bilateral primary ocular malignant melanoma. Report of a case. Trans Am Ophthalmol Soc 1949; 47: 80-92.

8 Shine FW. New York Eye and Ear Clinical Report 1930; 1: 31.

9 Reese AB. Tumors of the Eye. New York: Hoeber, 1951: 222.

10 Lau T. Das primäre doppelseitige maligne Melanom der Choriodea. Klin Monatsbl Augenheilkd 1981; 179: 333-5.

11 Oosterhuis JA. Primary choroidal and cutaneous melanomas, bilateral choroidal melanomas, and familial occurrence of melanomas. Br J Ophthalmol 1982; 66: 230-3.

12 Migdal C, Macfarlane A. Bilateral primary choroidal melanoma. Br J Ophthalmol 1984; 68: 268-71.

13 Callender GR. Malignant melanotic tumours of eye: study of histologic types in 111 cases. Ophthalmology (Rochester) 1931; 36: 131-42.

14 Gallie BL. Report of the second international symposium on retinoblastoma. Acta XXIV International Congress of Ophthalmology, San Francisco. Philadelphia: Lippincott, 1982: 2: 952.

Accepted for publication 11 April 1985. 